\title{
Speed Control of Dual Induction Motor Using Five Leg Inverter
}

\author{
Gayatri Chavan ${ }^{1}$, and Sridhar. $\mathrm{S}^{2}$ \\ ${ }^{1}$ PG Student, EEE Dept., M S Ramaiah Institute of Technology, Bangalore, India \\ ${ }^{2}$ Associate Professor, EEE Dept., M S Ramaiah Institute of Technology, Bangalore, India
}

\begin{abstract}
Over the past decade, research efforts have been made to decrease the number of power electronic devices needed in multi-motor drive systems in order to condense the overall complication and cost of the drive. This paper proposes speed control for a dual three-phase induction motor system driven by five-leg voltage source inverter (FL-VSI) which is used in industrial manufacturing processes. Industrial applications frequently need a number of variable speed electric drives. This technique uses five-leg inverter instead of using conventional two three phase inverters. In the majority of cases, these multi-motor drive systems need independent control of individual motors. It is shown recently that it is possible to separately control two three-phase induction machines supplied through a five-leg voltage source inverter, with one inverter leg being common to both machines. The entire performance of the speed control for the five leg voltage source inverter fed dual-motor drive system is investigated using MATLAB/SIMULINK software.
\end{abstract}

\section{Introduction}

Dual-motor drive systems have received significant attention in recent years for the fact of reduced number of devices, size, and losses in the inverters. Various topologies like four leg inverter system, mono-inverter dual-parallel system and nine-switch inverter system have been researched extensively for dual motor drive system. The advantages of these systems are:

1. Reduced switching losses.

2. Reduced volume of the whole system

3. Less switching devices.

4. Increased efficiency

Traditionally, 3 phase load control methods are of two types.

a. Use of individual inverters to control the loads separately.

b. Use of single inverter to drive 2 loads.

The disadvantage of the first method is that the number of switching devices increases, volume increases, more controllers requires, more losses and lesser efficiency.

The advantage of second method is that, both the loads can be connected in parallel, which reduces the number of switches, size, losses are reduced as compared to the first case, while the efficiency is improved.

This paper proposes five legs voltage source inverter (FL-VSI) supplying the two induction motors is proposed. Five leg VSI can:

1) Reduce the number of power electronic devices.
2) Reduce the overall complexity and therefore the cost.

In the FL-VSI dual-motor drive system, as shown in Fig. 1 , one phase of each motor is connected to the common leg of the FL-VSI. The other two inverter legs are connected to the remaining phases of each motor. The peak value of the common leg current can be higher than the other legs depending on the operating conditions.

Many control methods have been proposed for FL-VSI dual-motor drive system for improving the voltage utilization factor and independent control. Some of them are Direct Torque Control (DTC) method, space vector modulation, hysteresis control method, double-zero sequence (DZS) method and two-arm modulation method.

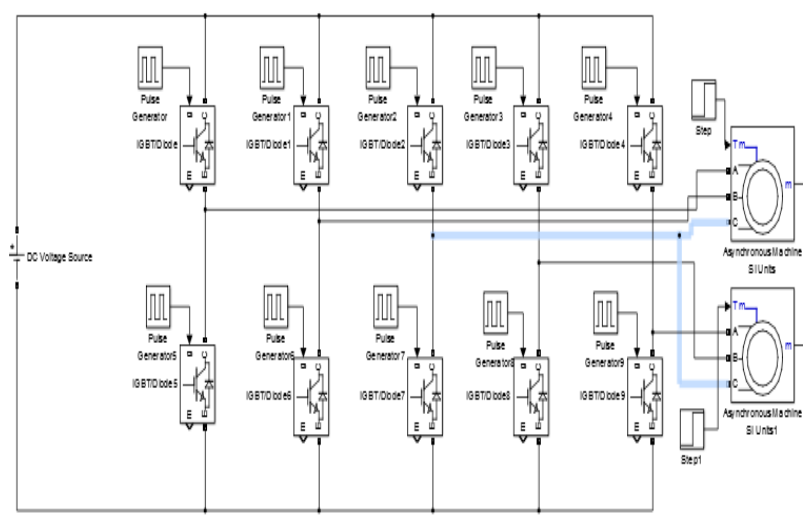

Fig. 1: Circuit configuration FL-VSI motor drive

\footnotetext{
* Corresponding author: sridhars@msrit.edu
} 


\section{Proposed Concept}

Fig. 1 presents the simulation circuit of the FL-VSI. It consists of a DC source, two induction motors, and the FL-VSI. Each leg of the inverter is composed of two IGBT switches with anti-parallel connected freewheeling diodes used to ensure a negative current path through the switches, and in total of 10 semiconductor switches and ten diodes. During operation of the inverter there are $32\left(2^{5}\right)$ possible switching configurations to prevent short-circuit on the dc-supply or open circuit on the load terminals. It should be ensured that the switches of same leg of the inverter should not be turned on simultaneously, as it would result in a short circuit across the DC voltage supply. DC supply is rated at $400 \mathrm{~V}$. In order to avoid undefined states in the FL-VSI and undefined $\mathrm{AC}$ output line voltages, the switches of any leg of the inverter cannot be switched off simultaneously as this will result in voltages that will depend upon the respective line current polarity. In Fig. 1, two machines share the inverter leg $\mathrm{C}$. Inverter legs $\mathrm{A}$ and $\mathrm{B}$ are connected directly to phases $\mathrm{A}_{1}$ and $\mathrm{B}_{1}$, respectively, of the machine-1 $\left(\mathrm{M}_{1}\right)$. Inverter legs $\mathrm{D}$ and $\mathrm{E}$ are connected to phases $B_{2}$ and $C_{2}$, respectively, of the machine-2 $\left(M_{2}\right)$. Switching functions $\mathrm{Sf}_{\mathrm{j}}$ are defined as $\mathrm{Sf}_{\mathrm{j}}=1$ when the upper switch is $\mathrm{ON}$ and $\mathrm{Sf}_{\mathrm{j}}=0$ when it is OFF.

\subsection{Variation of speed by varying load torque}

Variation of speed by varying load torque configuration is shown in Fig. 2. Phase delay of $36^{0}$ is given for all gate pulses as ten switches are there in five leg inverter $(360 / 10)$. Both motors of $10 \mathrm{HP}, 1440 \mathrm{rpm}, 50 \mathrm{~Hz}$ frequency ratings are selected. DC supply of 400 volts is applied as input to the inverter.

$$
\begin{gathered}
\text { Power }=7.5 \mathrm{KW}, \mathrm{N}=1440 \mathrm{RPM} \\
\text { Power }=\text { Torque }(\mathrm{T}) * \text { angular speed }(\omega) \\
\omega=\left(2 * \mathrm{Pi}^{*} \mathrm{~N}\right) / 60 \\
\omega=150.7996 \mathrm{radians} / \mathrm{sec} \\
\mathrm{T}=\mathrm{P} / \mathrm{W} \\
\mathrm{T}=49.736 \mathrm{~N}-\mathrm{m}
\end{gathered}
$$

$\mathrm{T}=49.736 \mathrm{~N}-\mathrm{m}, \mathrm{T} / 2=24.86 \mathrm{~N}-\mathrm{m}, \mathrm{T} / 4=12.434 \mathrm{~N}-\mathrm{m}$, Torque at final it will be zero. At starting both the motors will run at synchronous speed i.e., at no load condition. After 5 seconds it will run at full load torque and speed will decrease automatically.

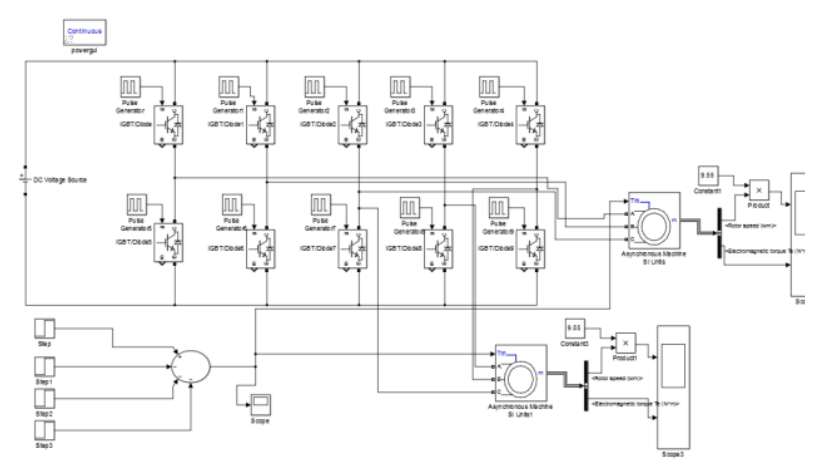

Fig. 2: Five leg inverter with varying torque
Torque is inversely proportional to speed. At 10 seconds motor will be at half load torque, speed will increase again. Again at 15 seconds motor will be at quarter load torque then speed will increase again. And finally at 20 seconds torque will be zero i.e., no load condition and speed will reach again to rated speed.

Parameters of both the motors shown in fig. 3 and pulse generation blocks are shown in fig. 4 . Both motors are of same ratings such as $10 \mathrm{HP}, 400 \mathrm{~V}, 50 \mathrm{~Hz}$, and $1440 \mathrm{rpm}$. And for pulse generation block frequency is $50 \mathrm{~Hz}$, so time is (1/50) 0.02 seconds. Pulse width is taken as $50 \%$. Phase delay for each switch is $36^{0}$ as shown in fig. 4 .

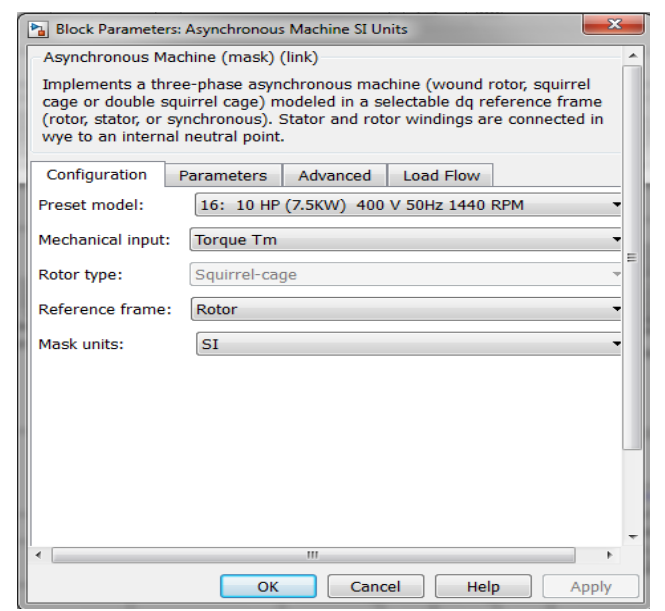

Fig. 3: Ratings of both motors

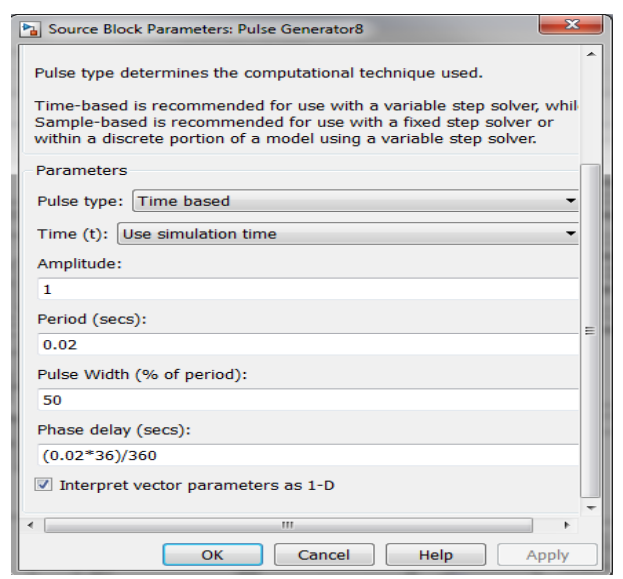

Fig. 4: Parameters of pulse generator

Load torque is varied in steps. First 5 seconds it is zero torque, 5 to 10 seconds full load, 10 to 15 seconds half load, 15 to 20 seconds quarter load and finally 20 to 25 seconds again to no load. Full load torque step block parameters shown in Fig. 5 and half load torque step block parameters shown in Fig. 6. 


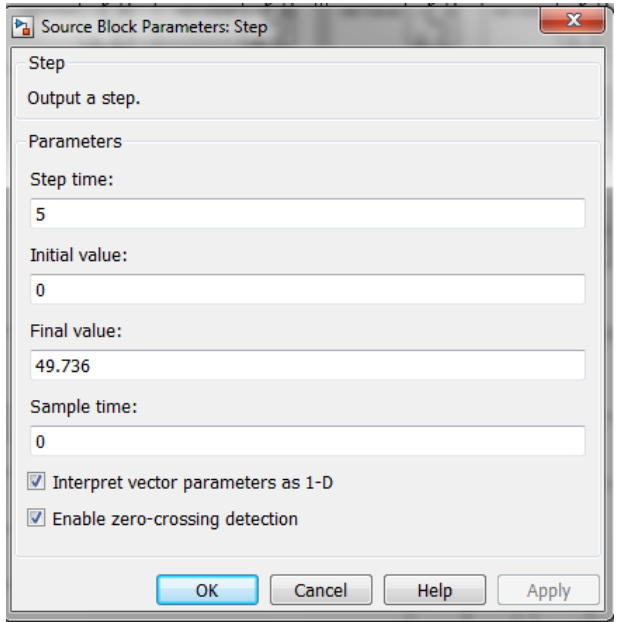

Fig. 5: Step block parameters with full load torque

\begin{tabular}{|c|c|}
\hline Source Block Parameters: Step1 & 28 \\
\hline \multicolumn{2}{|l|}{ Step } \\
\hline \multicolumn{2}{|l|}{ Output a step. } \\
\hline \multicolumn{2}{|l|}{ Parameters } \\
\hline \multicolumn{2}{|l|}{ Step time: } \\
\hline \multicolumn{2}{|l|}{10} \\
\hline \multicolumn{2}{|l|}{ Initial value: } \\
\hline \multicolumn{2}{|l|}{0} \\
\hline \multicolumn{2}{|l|}{ Final value: } \\
\hline \multicolumn{2}{|l|}{24.86} \\
\hline \multicolumn{2}{|l|}{ Sample time: } \\
\hline \multicolumn{2}{|l|}{0} \\
\hline \multicolumn{2}{|l|}{$\nabla$ Interpret vector parameters as 1-D } \\
\hline \multicolumn{2}{|l|}{$\nabla$ Enable zero-crossing detection } \\
\hline OK Cancel & Help \\
\hline
\end{tabular}

Fig. 6: Step block parameters with half load torque

Fig. 7 shows pulses of first five switches which are given to gates of each IGBT which will trigger the switches and Fig. 8 shows the pulses of pulse generator 6-10.

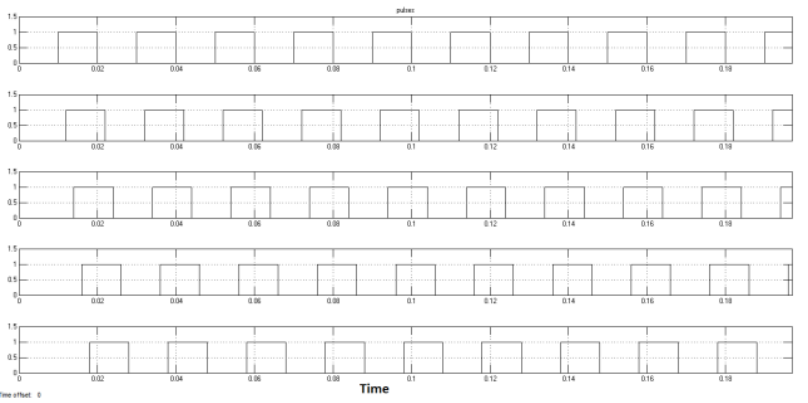

Fig. 7: Pulses of pulse generators 1-5

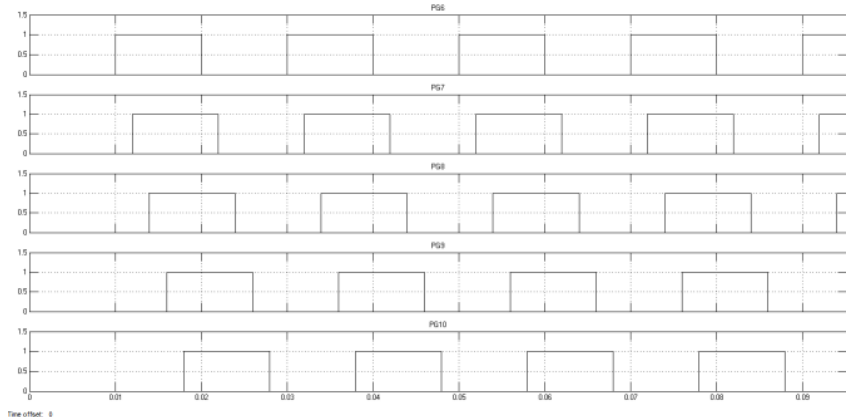

Fig. 8: Pulses of pulse generators 6-10

The pulses are phase shifted by $36^{0}$ each. Fig. 9 shows the line to line voltages of all five lines i.e., $\mathrm{V}_{\mathrm{ab}}, \mathrm{V}_{\mathrm{bc}}, \mathrm{V}_{\mathrm{cd}}$, $\mathrm{V}_{\text {de, }}, \mathrm{V}_{\text {ea. }}$. DC supply is given as $400 \mathrm{~V}$ so the peak value of voltage is $400 \mathrm{~V}$.

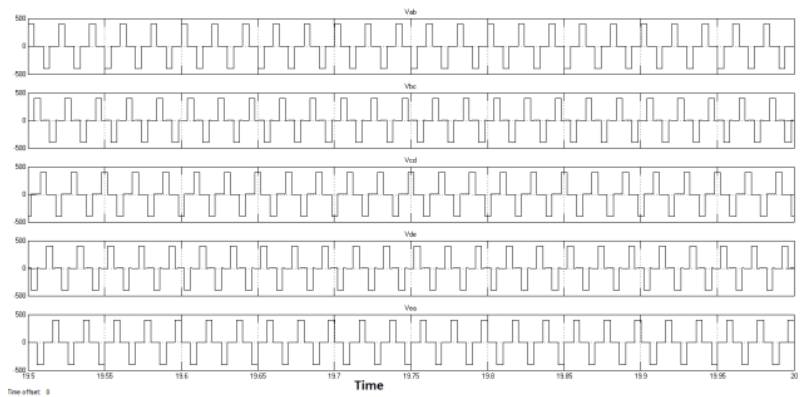

Fig. 9: Line to line voltages $\left(\mathrm{V}_{\mathrm{ab}}, \mathrm{V}_{\mathrm{bc}}, \mathrm{V}_{\mathrm{cd}}, \mathrm{V}_{\mathrm{de}}, \mathrm{V}_{\mathrm{ea}}\right)$

At starting both motors are at no load condition till 5 seconds i.e., $0 \mathrm{~N}-\mathrm{m}$, from 5-10 seconds it runs at full load i.e., $49.736 \mathrm{~N}-\mathrm{m}$, from $10-15$ seconds it runs at half load i.e., $24.86 \mathrm{~N}-\mathrm{m}$, from $15-20$ it runs at quarter load i.e., $12.434 \mathrm{~N}-\mathrm{m}$ and finally $20-25$ seconds again it will run at no load condition as shown in Fig. 10.

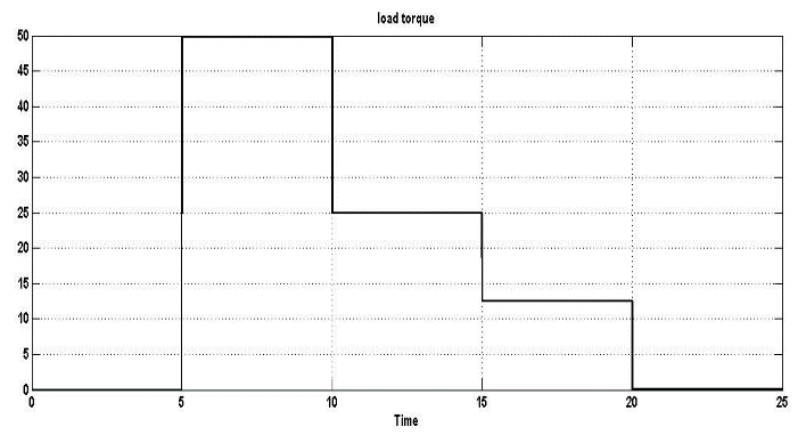

Fig. 10: Load torque variation from full load torque to no load

Fig. 11 and Fig. 12 shows the speed and torque waveforms of both the motors. As the load torque decreases speed will increase, and vice versa. 

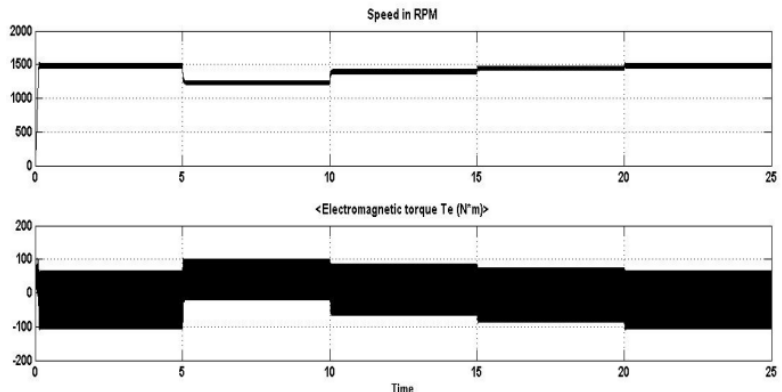

Fig. 11: Speed and electromagnetic torque output of motor-1
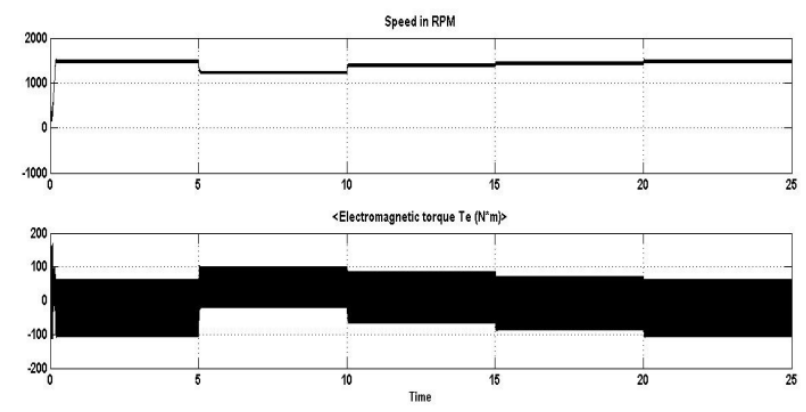

Fig. 12: Speed and electromagnetic torque output of motor-2

\subsection{Speed control of dual induction motor using control system}

The speed control of induction motors plays very important role in many industrial applications. So controlling of speed of both the motors simultaneously using five leg inverter is achieved with the help of controllers. The pulses to the IGBT switches are varied using PWM method. The PI controller is used to vary the PWM. The circuit diagram of the complete drive system with controllers is given in Fig. 13. For speed control of both the motors actual speed is taken as feedback to compare with a reference speed.

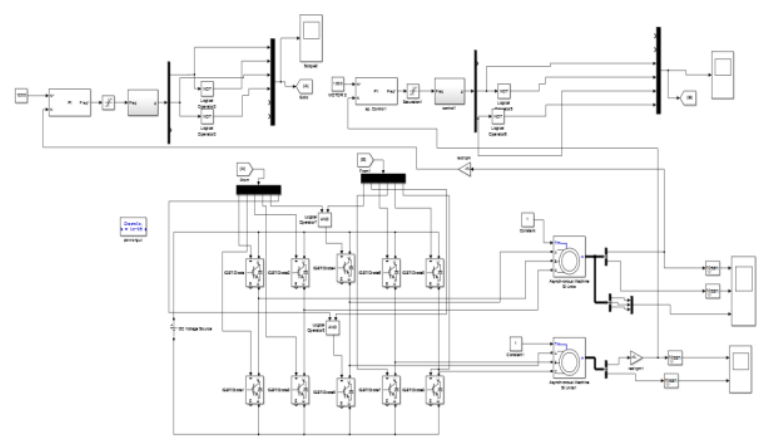

Fig. 13: Circuit diagram of five leg inverter with dual motor and controller

To convert the actual speed from radians to RPM it is multiplying with $[60 /(2 *$ pi $)]$. The feedback speed which was taken from the motors is given to PI controllers to compare with the reference speed. Reference speed is given as 1200 RPM for motor 1 and 500 RPM for motor 2 as shown in Fig. 14. Actual speed which is taken from both the motors and reference speed which should be the output is given to the PI controllers.

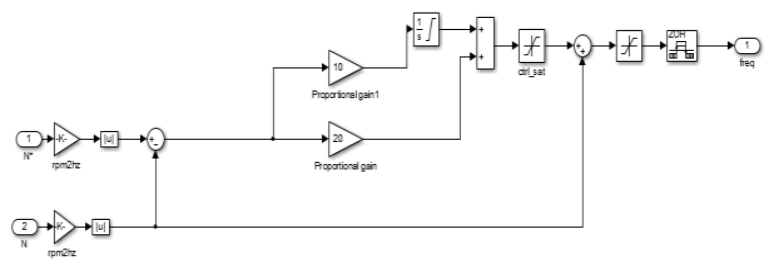

Fig. 14: PI controller system

PI controller in the feedback control loop calculates the error by taking the difference between the outputs of the system. The $\mathrm{K}_{\mathrm{P}}$ and $\mathrm{K}_{\mathrm{i}}$ values are tuned and found to be 20 and 10 respectively. Finding an error between actual speed and the reference speed is done. Saturation block is used to limit the input signal to the upper and lower limit saturation values. Error which is calculated in PI controller is given to the next controlling part which is named as frequency. The frequency which is in hertz is converted into radians by multiplying it with $2 * \mathrm{Pi}$. Fig. 15 shows the pulse width modulation technique. All the three phases are phase shifted by $120^{\circ}$. All the sinusoidal waves are compared with the carrier wave. If sinusoidal waves are greater than carrier signal then the pulses will be generated or else no pulses are generated. The same procedure will continue for all three waveforms. In this way the pulses to fire IGBTs are generated and it will control the speeds which are required. NOT gate is used to ensure that no two switches of the same leg are triggered simultaneously.

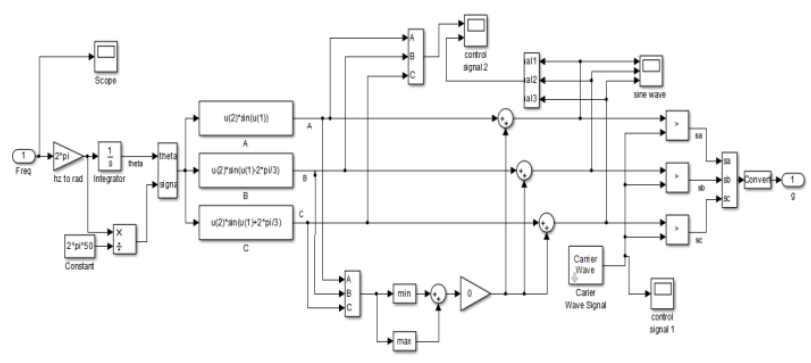

Fig. 15: PWM method for generating pulses

Pulses generated using pulse width modulation (PWM) technique for both the motors is as shown in Fig. 16. Generated pulses are given to switches in sequence as given.

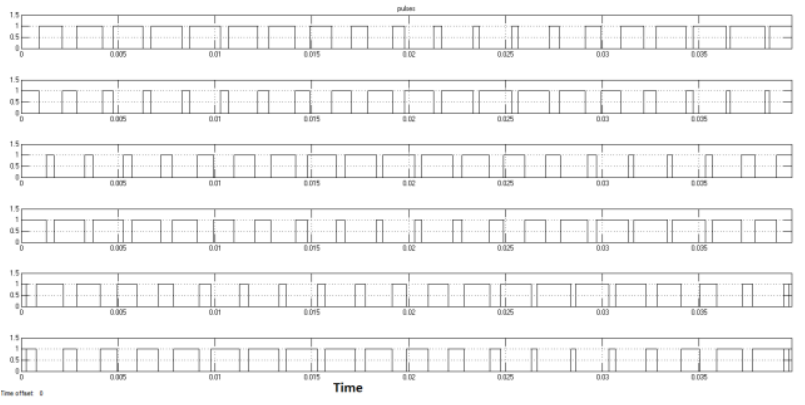

Fig. 16: PWM pulses for motors 


\section{Simulation results}

Fig. 17 and Fig. 18 shows the pulses which are generated by the PWM method and are given to all ten switches to get an appropriate speed which are required. Fig. 17 shows the pulses of switches $\mathrm{S}_{1}, \mathrm{~S}_{6}, \mathrm{~S}_{3}, \mathrm{~S}_{8}$ and $\mathrm{S}_{5}$ and Fig. 18 shows the pulses of switches $\mathrm{S}_{7}, \mathrm{~S}_{2}, \mathrm{~S}_{9}, \mathrm{~S}_{4}$ and $\mathrm{S}_{10}$ respectively.

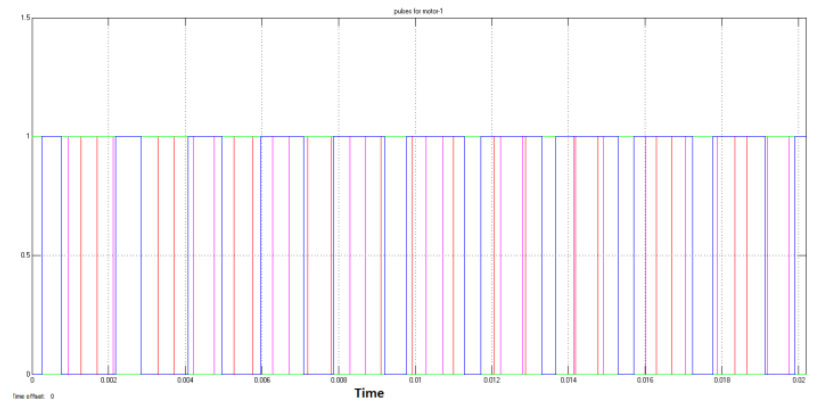

Fig. 17: Pulses of switches $S_{1}, S_{6}, S_{3}, S_{8}$ and $S_{5}$

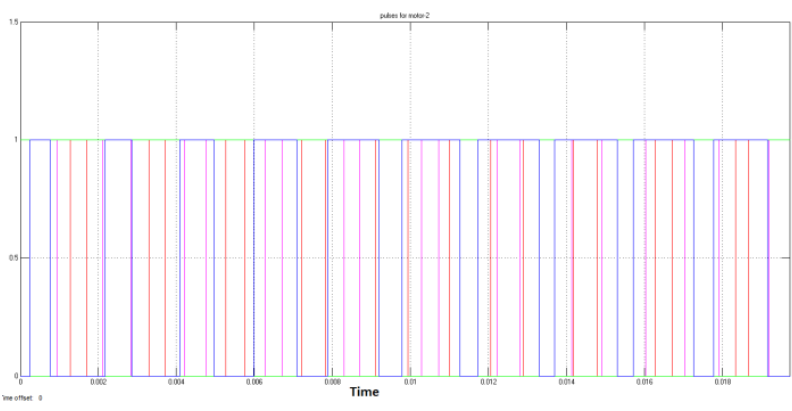

Fig. 18: $P$ ulses of switches $S_{7}, S_{2}, S_{9}, S_{4}$ and $S_{10}$

Fig. 19 and Fig. 20 shows the line to line voltages of motor-1 and motor-2 respectively.

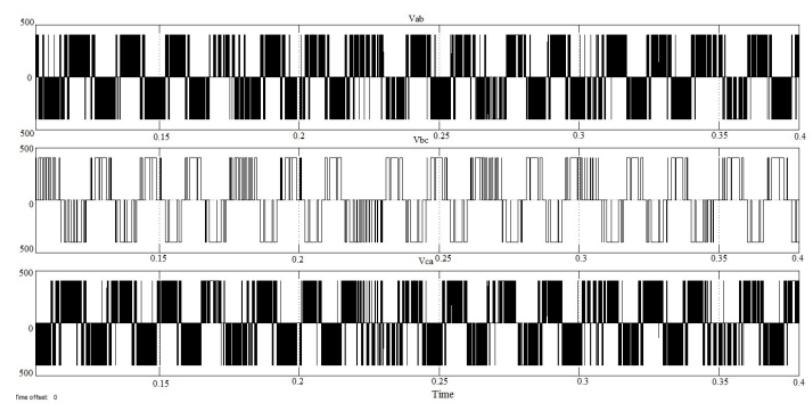

Fig. 19: Line voltages of motor-1
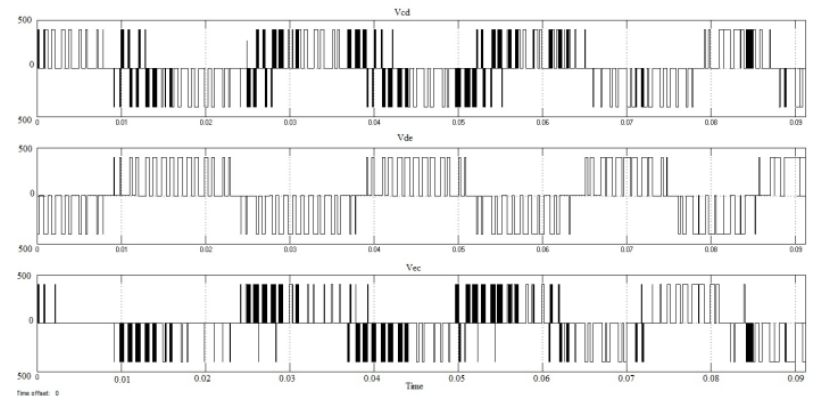

Fig. 20: Line voltages of motor-2
The speed of both motors are shown in Fig. 21 and Fig. 22 respectively. The speed of motor 1 is set as 1200 RPM and motor 2 as 500 RPM.

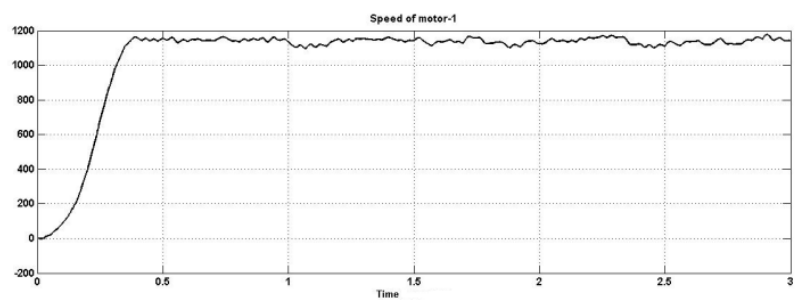

Fig. 21: Speed waveform of motor-1with 1200 RPM

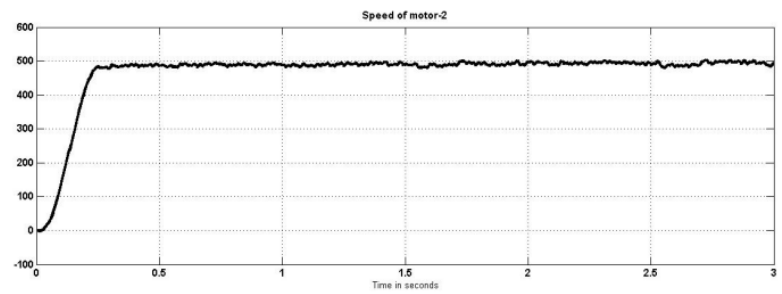

Fig. 22: Speed, waveform of motor-2 with 500RPM

Fig. 23 and fig. 24 shows the speed waveforms for both the motors with the reference speed of 1000 RPM for motor 1 and 800 RPM for motor 2 in the circuit. For controlling speeds of both the motors comparison of both actual speed and reference speed has done. For this circuit reference speeds 1000 RPM for motor 1 and 800 RPM for motor 2 are given.

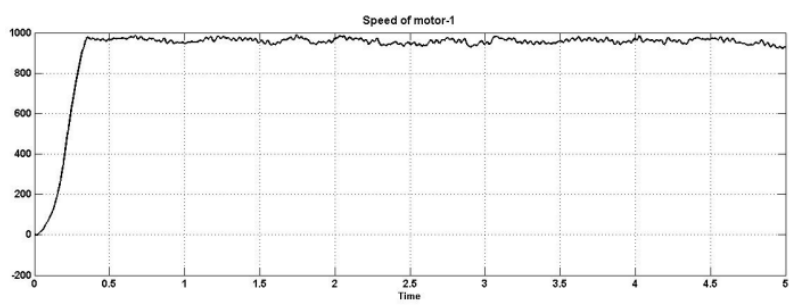

Fig. 23: Speed waveform of motor-1 with 1000rpm

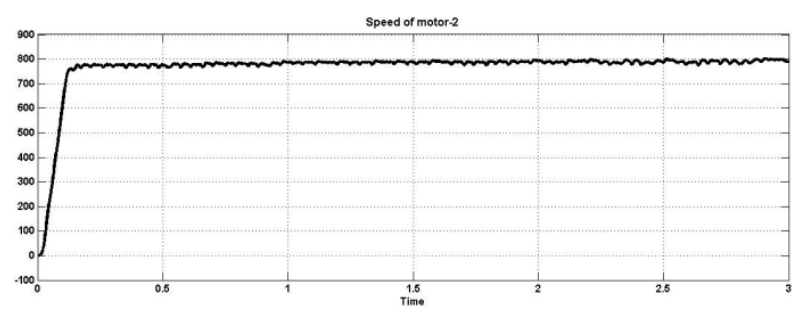

Fig. 24: Speed waveform of motor-2 with $800 \mathrm{rpm}$

\section{Conclusion}

This paper proposes a speed control method for dual motor system using FL-VSI. DC supply is given to the five leg inverter system. One of the legs is common for both the motors. For controlling speed of both the motors simultaneously speed of both the motors are taken as feedback. With the help of PI controllers the error signals 
between the reference speed and actual speed is calculated for both motors. PWM method is used for generating pulses. In these controllers three sinusoidal waves which $120^{\circ}$ apart from each other are generated and are compared with carrier signal to generate the pulses which are used to fire the switches. These pulses will help to give the speeds which are required for proper operation. Reference speed for motor-1 is given for motor 1 as 1200 RPM and for motor 2 as 500 RPM. Finally the speed output is obtained and controlled. And this control system is checked for different speeds for both the motors like motor-1 speed as 1000 RPM and motor- 2 speed as 800 RPM.

\section{References}

1. S. Hu, Z. Liang, W. Zhang, and X. He, "Research on the integration of hybrid energy storage system and dual three-phase PMSM drive in EV," IEEE Trans. Ind. Electron, vol. 65, no. 8, pp. 6602-6611, (2018)

2. Bekheïra Tabbache, Mohamed Benbouzid Khoudir Marouani1, "A Decoupled Control of 5-Legs PWM Inverter Feeding a two Induction Motors-based Electric Vehicle Power train", Abdelaziz Kheloui Ecole Militaire Polytechnique, UER ELT, 16111 Algiers, Algeria (2016)

3. Young-Seol Lim, Student Member, IEEE, JuneSeok Lee, Member, IEEE, and Kyo-Beum Lee, Senior Member, IEEE, "Advanced Speed Control for a Five-Leg Inverter Driving a Dual-Induction Motor System”, vol. 66, no. 1, January (2019)

4. Ahmad Anad Abduallah, Mohammed Meraj, Mohammed Al- Hitmi, Atif iqbal, "Space vector pulse width modulation control techniques for a five- phase quasi-impedance source inverter", (2017)

5. A.R. Barati, M. Moslehi, D. Arab Khaburi, "ZSource Five Leg Inverter", (2013)

6. Ph. Delame, A. Bouscayrol, B. Franqois, "Control implementation of a five-leg voltage-source-inverter supplying two three-phase induction machines", (2003).

7. Yashan Hu, Shoudao Huang, Senior Member, IEEE, Xuan Wu and Xuefei Li, "Control of Dual ThreePhase Permanent Magnet Synchronous Machine Based on Five-Leg Inverter", (2019)

8. Meiji University Higashi-mita, Tama-ku Kawasaki, Japan, "Characteristics of Speed Control of Two Induction Motors Fed by a Five-leg Inverter with Space Vector Modulation", (2013)

9. Yusuke Ohama, Kazuo Oka, and Kouki Matsuse "Characteristic of Independent Two Induction Motor Drives Fed by a Five-Leg Inverter", Department of Electrical and Electronic Engineering, Meiji University, (2009)

10. Yang Mei, Shuaiwei Feng" An Optimized Modulation Method for a Five-Leg- Inverter for Dual Induction Motor Drives", Beijing North China University (2016) 